\title{
Principles Of Service Systems: An Ontological Approach
}

\author{
Harry Katzan, Jr., Savannah State University, USA
}

\begin{abstract}
This paper delineates the principles of service systems, based on an ontological foundation of the subject matter developed independently of a particular endeavor, that are required to enable communication among researchers and assist in the ongoing theoretical development of the constituent topics. The paper begins with the presentation of service elements and progresses through the various topics until the requisite concepts, relations, and vocabulary are formulated. The subjects are presented in a developmental manner to promote clarity and readability by a broad service science audience and to support research in the discipline.
\end{abstract}

Keywords: Service, service systems, service science, service ontology.

\section{SERVICE CONCEPTS}

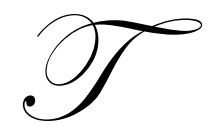

he basic concepts of service, service systems, and service science have been well-developed. (Sampson and Froehle 2006, Maglio and Zysman 2007, and Katzan 2008b) To fully benefit from the service perspective, however, an ontological foundation is required to facilitate communication among researchers and assist with the ongoing theoretical and pragmatic development of the discipline. To some extent, an ontology is dependant upon a particular point of view, and this paper seeks to identify a set of rigid descriptors that link to the various underlying concepts. We are going to take the view that a comprehensive depiction of the application domain is as important in service ontology as is the taxonomy used to describe it.

\section{Service}

In a widely distributed paper on the science of service, Spohrer and associates (Spohrer 2007b) give several characteristics of an elementary service event: customer participation, simultaneity, perishability, intangibility, and heterogeneity. Customer participation refers to the co-production of the service experience and the co-creation of service value. Simultaneity denotes the fact that a service is produced and consumed simultaneously. Perishability refers to time perishable capacity from the provider's viewpoint and opportunity loss from the client's perspective. Intangibility normally denotes the obvious fact that goods are not produced by a service event. ${ }^{1}$ Lastly, heterogeneity refers to the variation in a service from client to client and from provider to provider, along with the recognition that a service system is a complex system that can be mediated by information technology. This seemingly simple definition belies the complexity of the situation, since there is a multiplicity of service definitions, based on existential considerations. A service is a socially constructed temporal event, and within that domain, an objectivist view of the subject matter is adopted. Service exists and possesses an implicit lifecycle comprised of design, development, analysis, and implementation, similar in nature to most technical innovations. Specificity will be added to the service lifecycle model in a later section. Moreover, a service evolves and is subject to descriptive and nominative modalities. As with traditional social activities, a service can be analyzed and measured. In fact, a service is an economic entity that possesses demonstrable value to the participants, in particular, and to organizations and society, as a whole.

\footnotetext{
${ }^{1}$ The tangible/intangible terminology is unfortunate. In this instance, tangible implies a product. and intangible denotes a service. In later sections, tangible denotes demonstrable value, and intangible implies an affective state of awareness that differs between individuals.
} 
Services are indigenous to the existence of modern society. In fact, if one replaces the concept of labor with that of service, the principles of service science can be derived from the essential work of Adam Smith (Smith 1776), most pointedly in his notions of "value in use" and "value in exchange."

\section{Social Constructivism}

Social constructivism is a theory of knowledge (epistemology) based, at least in part, on the social and material setting in which a belief is produced or maintained. In social constructivism, individuals and groups participate in a perceived reality, and create an element of knowledge, as espoused by the philosophical doctrine of Equal Validity. (Boghossian 2006, Bergquist 1993) Equal validity suggests the notion that other means of knowing exist in addition to the factual predominance of scientific investigation. Consider an example of a simple wooden chair developed in antiquity and regarded as a place to sit and pile books. A chair is made from a type of wood that we as a society have discovered as being useful to the purpose. Wood exists as a natural phenomenon independently of chairs and the social setting in which it exists. The precise form and substance of a chair, however, is a socially constructed form of knowledge that none but the hardened skeptic would deny is a valid form of knowledge. Service systems are socially constructed forms of interaction wherein entities exchange beneficial forms of action through the combination of people and technologies that adapt to the changing level of information in the system. As such, reality constructed through social mechanisms is a dynamic process replicated and maintained by social interactions within a service and between services.

Service systems are actual social phenomena that existed, in part, before the development of service science and are analogous to economic systems that existed before the development and study of economics. Both types of systems are governed by events in their operational environments and are continually being created, modified, and retired. A service is neither synthetic (like synthetic rubber or various chemical compounds) nor artificial (like artificial intelligence in the computer field). Services are observable, and through a process of shared reality, concepts are developed that lead to classes of service and subsequently instances of that service. We are going to apply epistemological concepts to develop a service ontology that adheres to the hypothetico-deductive modality of scientific research. (Sutherland 1975)

\section{Service Universe}

A service universe is a collection of services under consideration at a given point in time by a person, group, organization, or even a society. A service universe is typically a set of services, organized in some fashion to achieve a discernable purpose. However, that need not necessarily be the case, and could be a disparate collection of temporal service events, or even a combination of the two categories. The notion of a service is problematical, because there are differing points of view on exactly what constitutes a service, even though most persons could reliably identify a service when confronted with one. Professional, technical, and scientific people are service providers, even though they do not normally think of themselves in that fashion. Call centers, consulting companies, and utilities also do service, but dry cleaners and fast-food restaurants do them, as well. The subject is important because $80-90 \%$ of the working population in developed countries is engaged in services, and they are also consumers of services.

A simple question on this subject, such as "What is a service?' can yield a surprisingly large number of different answers. Here are a few instances that would immediately come to mind:

1. An action performed by one person or group on behalf of another person, organization, or group.

2. A generic type of action, such as a medical service or a web service.

3. The process of performing some action classified as a service.

4. The result of an action - typically a change affecting an object or person.

5. The utility of a change affecting a person or object - the value proposition.

6. An organization behaving in a prescribed way to benefit or operate in the best interests of a person or group.

7. A promise, contractual agreement, or obligation to perform a specified action in the future as a response to a triggering event. 
8. The deployment of service assets for the benefit of service participants, commonly regarded as provider and client.

There are two fundamentally different points of view: the global view and the local view. The global view refers to the notion of a system comprised of interacting and complementary services. One could consider the global view as an external service description, useful for determining how a collection of services functions in order to benefit various people, organizations, and business processes. This view is analogous to macroeconomics. The local view describes and delineates the steps in a distinct service process, emphasizing the service participants and the complementary roles they play in the service event. This view is analogous to microeconomics. A discrete service fits nicely into one of several mutually exclusive categories based on service characteristics that can be distinguished with a service DNA. (Katzan 2008a) In this paper, we are going to adopt global and local viewpoints and structure the ontology according to that dichotomy. Between the global and local points-of-view, we are going to develop a consistent set of underlying concepts, relationships, and language elements.

\section{Service Systems}

A singular service event is a form of social organization in which two or more resources interact to achieve an agreed-upon purpose, where a resource can be a person, organization, or an element of technology. ${ }^{2}$ The service is the unit of exchange in the interaction that is established to produce value for each of the participants. (Spohrer 2007b) The resources are commonly referred to as service entities or entities. Based on this assessment, we can propose the following definition:

Definition of Service Two entities collaborate and what is produced from the interaction is a service, if and only if

- $\quad$ Both parties participate in the exchange

- $\quad$ Both parties benefit from the exchange such that value is co-created in a complementary form

- $\quad$ The action of the service is complementary

- $\quad$ The parties assume complementary but differing roles

- $\quad$ The roles are commonly known as provider and client.

The provider role is regarded as a serving activity, and the client role is, likewise, regarded as a receiving activity. Moreover, the collaboration adapts to the win-win model of economic exchange, since value is co-created for both participants. The complementary form of activity is intended to distinguish it from a supplementary form in which participants operate as partners to perform a stated function. For example, a physician and a patient exhibit complementary roles in a service, whereas a scenario in which two masons work together to build a structure represents a supplementary form of behavior. A singular service event is the most elementary form of a service system. (Spohrer 2007)

A unified service is a process that takes input and produces output. In between the input and the output, there exists one or more steps that constitute the service process. (Sampson and Froehle 2006, Katzan 2008b) The steps in a service process often include other services leading to the concept of a service system.

A service system is a collection of resources, economic entities, and other services capable of engaging in and supporting one or more service events. Services, i.e., service processes, may interact or they may be included in a service value chain. This is a recursive definition of a service system that would support the following modalities of service operation: tell me, show me, help me, and do it for me. Service systems are inherently multidisciplinary, since a service provider may not have the knowledge, skill, time, resources, and inclination to perform all of the steps in a service process and require the services of an external service provider.

As introduced above, service systems are social constructs that commonly encompass other services and are components of a larger reality. An organizational structure of this particular genre could be regarded from either of two points of view: as an economy or as an adaptive social structure. As an economy, it is a system of

\footnotetext{
2 This is a necessary but not a sufficient definition of a service.
} 
relationships that govern the availability of scarce resources and operate under conditions of efficiency and effectiveness. As an adaptive social structure, the efficacy of a service event depends upon the dynamic environment in which an organization operates. (Selznick 1948) A service system is a cooperative dynamically changing formal system, with a porous boundary so that the environment it which it resides has a deterministic effect on its behavior.

A unified service system requires some sort of organizational entanglement so that an enterprise can invest prudently and produce predictable outcomes. Accordingly, research into the mechanics of service systems requires three things: an appropriate operational platform, a design theoretic formulation, and an ontology of service and service systems, which is introduced in subsequent sections.

\section{Service Science}

With regard to academic disciplines, there is an old saying that goes somewhat as follows: "If it has the word 'science' in its title, then it isn't science." It would appear that service science is an exception. There are two fundamental questions: "What is science, anyway?" and "What does a conceptualization of science have to do with service?"

In an earlier debate concerning computer science, Newell, Perlis, and Simon (Newell 1967) state, "Wherever there are phenomena, there can be a science to describe and explain those phenomena." Further, Kuhn (Kuhn 1962) states, "Science is the agreed upon methods and standards of rigor used by a community to develop a body of knowledge that accounts for observable phenomenon with conceptual frameworks, theories, models, and laws that can be empirically tested and applied within a world view or paradigm." Moreover, since service systems are an observable and evolving phenomena, subject to the dynamics of the economic world, the development of a science of service, replete with its own frameworks, models, and theories, is an essential element in a total world view. (Spohrer 2007a)

Epistemologically, there exists a conceptual service universe in which observable services and service systems operate. One can view this service universe in a manner similar to which we view the physical universe described by physics and chemistry. The modus operandi in those disciplines is to abstract a piece of that universe and study it as a sub-discipline. Mechanics, heat, and sound are elementary sub-disciplines that fall into the discipline of physics.

The services in the service universe can be viewed metaphorically as entities floating around in a service space waiting for the chance to be called upon to execute as a singular event, as a component of a service system, or as a chance to be called upon interactively. Some services are used in more than one service system. Service science is a collection of models of sub-disciplines abstracted from the service universe, in much the same manner that the physical sciences are collections of sub-disciplines. The procedure in all cases is to take a piece of an existing system and put it under the microscope of academic scrutiny. Thus, a particular service or a service system is an abstraction of service science, as with the physical universe, and a service theory is a means of tying the various models together. On the other hand, if one views the entire amorphous service space as a service system, then service science could be alternately viewed as a basic abstraction of service systems, realizing, of course, that the ultimate objective is to study categories of service systems.

There are, of course, additional considerations regarding the phenomena of service and service systems. Services evolve and are continually being developed and modified. Service systems are affected through their porous boundaries by stakeholders, laws, and social customs. They also require formalization as important aspects of the discipline of service science.

\section{ONTOLOGY}

Ontology is a specification of "what is." In philosophy, use of the term reflects the study of being (or existence) and describes and delineates a collection of basic categories, and defines the entities and classes of elements within a category. In service science, ontology is a specification of a conceptualization used to enable 
knowledge sharing. Since ontology concerns existence, an ontological definition of a subject - perhaps a service category - reflects a materialization of a concept obtained through a shared reality, and not what it is called or how it is made or used. In this paper, the definition of ontology, as "a set of representational primitives with which to model a domain of knowledge or discourse," will be adopted. (Gruber 2008, Wikipedia 2009a) More specifically, ontology can be viewed as a data model that describes objects, classes, attributes, and relations. In his groundbreaking book on knowledge representation, John F. Sowa gives an appropriate definition for our purposes:

The subject of ontology is the study of the categories of things that exist or may exist in some domain. The product of such a study, called ontology, is a catalog of the types of things that are assumed to exist in a domain of interest $\boldsymbol{D}$ from the perspective of a person who uses the language $\boldsymbol{L}$ for the purpose of talking about $\boldsymbol{D}$. The types in the ontology represent the predicates, word senses, or concept and relation types of the language $\boldsymbol{L}$ when used to discuss topics in the domain $\boldsymbol{D}$. (Sowa 2000)

One common approach to the delineation of ontological elements is to divide the extant entities into groups called "categories." These lists of categories can be quite different from one another. It is in this latter sense that ontology is applied to such fields as theology, service science, and artificial intelligence. (Wikipedia 2009)

\section{Ontological Naming}

In the naming of ontological elements, it is important to note that there are two approaches to the use of nouns. In one philosophical school, nouns should refer to existent entities. In the alternate school, nouns are used as a shorthand as reference to a collection of object or events. For example the word mind would refer to a collection of mental states, and society would refer to a collection of people.

\section{Ontological Engineering}

Ontological engineering encompasses a set of activities conducted during conceptualization, design, implementation, and deployment of ontologies. (Dedvedzic 2002) Ontological engineering seeks to achieve the following goals in a given domain:

- Definition of terms

- $\quad$ Establishment of a body of domain knowledge

- $\quad$ Specification of coherent and expressive knowledge bases

In short, ontology defines the vocabulary of a problem domain and a set of constraints on how terms are related. It also gives data types and operations defined over the data types.

Most forms of ontology are expressed in an ontology language and share structural similarities, such as individuals, classes, attributes, relations, function, restrictions, rules, axioms, and events. The basic idea behind ontology languages is to allow software agents to communicate in a knowledge intensive computer-based environment: We are going to concentrate on the following components: (Guarino 1995, Wikipedia 2009)

Individuals referring to instances and objects

Classes expressed as sets, collections, and kinds of things

Attributes giving features and characteristics of individuals and classes

Relations that determine ways that individuals and classes relate

The components determine whether a specific ontology is a domain ontology or an upper ontology. In a domain ontology, a specific type would be relevant to particular category, such as in a medical or household category. In an upper ontology, a type would be applicable to all ontologies in the universe of discourse. In the service ontology, presented in the following section, we are going to be developing an upper ontology for service systems. 


\section{UPPER ONTOLOGY FOR SERVICE SYSTEMS}

The ontology of service systems is a developmental artifact for the study, design, analysis, and application of services. Essentially, a framework is needed to tie the elements together, so that they are applicable to a wide range of operational scenarios. (Alter 2008) The primary measure of an ontological determination is how it assists in delineating the value chain for services, comprised of people, technology, and organizations, and its relevance to education, government, business, and other social phenomena.

\section{Service Systems Lifecycle}

Service science is one of the few disciplines in which the basic principles and resultant theory apply to both small-scale and large-scale operations. We are going to proceed with that assumption. In its most basic form, a service is a value producing interaction between a service provider and a service client, consisting of a process conceptualized as a layered set of activities. (Ferrario and Guardino 2008) It is useful to conceptualize the layers according to the following global service system lifecycle:
- $\quad$ Service commitment
- $\quad$ Service production
- $\quad$ Service availability
- $\quad$ Service delivery
- $\quad$ Service analysis
- $\quad$ Service termination

Initially, we are going to be looking at services from a global view, where the lifecycle pertains to a set of generic services supplied by an economic entity, such as a governing body, a business, an institution, or an individual acting in a service capacity. Service commitment refers to the formal agreement to provide a class of services to a service audience by a principal or trustee with the proper administrative control over the service environment. The agreement to provide fire service by a municipality and the founding of a health clinic are common examples. Service production pertains to service provisioning, infrastructure, availability, quality management, and back-office processing. The producer is the agent of the principal in a prototypical principal-agent scenario. The principal and agent may be the same economic entity or different economic entities depending upon the scope of the service domain. The manager of a chain of restaurants and the medical director of a clinic are examples. Service availability is the time during which a service is available. Commitment does not necessarily imply availability, because of a variety of spatiotemporal events. Service delivery is the class of actions usually regarded as the service and is the layer where the service client comes into the picture. The doctor/patient relationship is a good example of this layer. The service provider, who could have a dual role as producer, is an agent of the producer as the primary source of service revenue and the primary provider of a service. Service analysis refers to measurement activities and the determination of value propositions needed to sustain service operations. Service termination reflects the inevitable consequence of a dynamic and evolving economic environment where a total service operation has to be retired, because of insufficient activity or realigned opportunities. The global lifecycle represents a provisioning perspective of service systems.

\section{Service Entities}

We are looking at five service entities: the service principal, functioning as a trustee of a service or a service system; the service producer, responsible for the availability, infrastructure, service provisioning, and backoffice processing; the service provider, charged with the application of resources for the benefit of another service entity: the service client, who has a complementary service relationship with the service provider; and the service object that may be the direct recipient of the result of the service process.

A service entity need not be a person, but can be a group, organization, business, governing body, educational institution, or a physical object, such as a possession or an element of computer software. 


\section{Service Commitment}

Service commitment is a guarantee by a principal to provide a set of actions that constitutes a service. A common example might be the promise of a mayor of a town to provide fire service to his constituents. (Ferrario and Guardino 2008) The principal can be an organization, such as a government, a medical group, an educational institution, a private service business, a consulting firm with a service-level agreement, and an ad hoc entity that provides service to other service entities. A service commitment may result from an explicit declaration, such as "I agree to provide said service to a receiving agent" or be implicit in a legal charter or understanding, such as a medical practice or financial institution. A service commitment may apply to all constituents in the principal's domain - perhaps to all families moving into a community or entering a service facility.

The committed service may not, and probably will not, be performed by the principal, who may rely on a service producer and an ensuing service provider known as a service agent to actually execute the service process. Thus, a service agent provides a service to the principal and to the service object. The service principal, producer, and provider may coincide or be distinct to some degree.

\section{Service Production}

Service production supports a service commitment by establishing service parameters, such as time, location, availability, infrastructure, provisioning, record keeping, and legal compliance and certification. Time and location are key factors in service delivery that are summarized through a service DNA, which partitions the service domain into mutually exclusive service categories. (Katzan 2008a) The principle element in service production is maintenance of the service infrastructure, consisting of physical facilities, operational procedures, satisfaction of legal requirements, competent provider provisioning, and dependable auxiliary service provisioning.

\section{Service Availability}

The availability of a service is dependent upon the inherent nature of the service commitment. The access to and duration of medical provisioning, banking, insurance, product warranties, and household service, as examples, probably differ in most cases. It is important to additionally note the significance of service commitment with regard to service availability. What a service principal commits to is the service content and not to its associated service process, scheduling, and other operational considerations.

\section{Service Delivery}

In order for a service provider and a client to co-create a service event, there must be some degree of locality to the situation, in the sense that the client travels to the provider, the provider travels to the client, the client and provider execute the service event in a third-party location, or they communicate via some form of interactive device and its corresponding media. Location is basic to service provisioning. When the client travels to the provider site, the location is termed a service factory and the client or the service object remain in the service factory for the duration of the service transaction. When the service object is left in the provider's facilities, the location is known as a service shop. The provider may travel to client facilities, as in the cases of custodial work or nursing home care. With information service, the provider may reside in a remote facility and provide access through a service portal.

A related consideration is the distinction between discrete service and continuous service. There are many edge cases. Insurance is commonly regarded as a continuous service, as is banking - except in the cases where the customer visits a bank branch. Medical provisioning, automobile maintenance, and household service are usually regarded as discrete services. In the latter case, when a service event is over, it's over. A follow-on service is regarded as another service event. 


\section{Service Analysis}

To some extent, all services consist of the application of resources, and the success of those services is dependent upon how efficiently and effectively those resources are applied in a normative manner to a specific problem domain. (Spohrer 2007a) Thus, measurement and analysis is required to assess both individual service interactions and the cumulative result of a set of service interactions. The basic tenet of service delivery is the following. The client starts out with expectations, and a service deliverer should start out off by assessing what those expectations are. However, not all service events are successful, so that a risk analysis should be performed by the providers and the client prior to a service engagement. In service analysis, the success of a service event is dependent upon how accurately the service providers and the client assess their roles.

Measurement and analysis are often the modus for judging service and service quality, and in an organizational setting, is achieved through service level agreements between complementary economic entities. For instances where implicit agreements persist, service analysis involves responsiveness, timeliness, and completeness - traditional metrics that have evolved through informal agreement.

\section{Service Termination}

In order for a service system to be successful, it must exist and persist. To exist, that service must satisfy the economic goals of provider, client, producer, and trustee in due consideration of the needs surrounding its competitors, partners (business or operational), employees, and investors. (Spohrer 2007a) The economic goals are known as the value proposition of the service consisting of the provider's sacrifice, the client's sacrifice, provider's exploitation, and the client's exploitation, from both short-term and long-term perspectives. (Alter 2008) Accordingly, a discrete service offering can be unsuccessful in either of four ways: (Spohrer op cit.)

- $\quad$ The client does not accept the provider's value proposition in light of its own.

- $\quad$ The client decides to engage in "self service'

- The client decides to accept service from an alternate source

- The client decides to forgo service

Thus, cumulative service decisions from within the client domain essentially determine the persistence of a service commitment.

\section{DOMAIN ONTOLOGY FOR SERVICE}

A discrete service event entails the commitment of resources for the benefit of a client. Each service event - frequently referred to as a service interaction - consists of a series of steps called the service process intended to achieve a particular goal. Within a given service category, the various service processes are similar within acceptable limits of variability.

\section{Basic Service Categories}

A service is a provider/client relationship (Katzan 2008b) that captures value for both participants that can be individuals, organizations, software, or a complex arrangement of the three, given as follows:

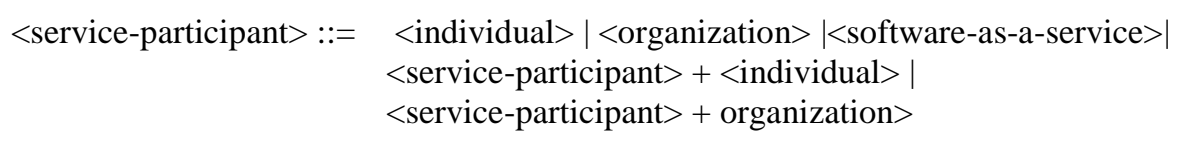

Service operations are customarily grouped into three classes: people processing, possession processing, and information processing. Within each domain, it is therefore important to view the client/provider relationship along the following dimensions: 
- $\quad$ Tangible vs. intangible

- $\quad$ Primary vs. secondary

- $\quad$ Facilitating vs. auxiliary

This approach focuses on the fact that a service event is a process consisting of primary and secondary services. (Sampson and Froehle 2006)

TANGible AND INTANGIBLE Service A tangible service is a provider/client event that results in demonstrable values to the service participants. With an individual service participant, this is a left-brain function (LBF). In retailing, it is the acquisition of a product including attendant activities that change the ownership attribute of the associated product. However, the value proposition for a product may be determined from the service it provides, rather than from the intrinsic value of its specific components. In pure service, such as a people and possession processing service, value is created through the work performed on behalf of the client by the provider. With information service, the service's value is derived from the transfer of information from service provider to the client. An intangible service provides value for a service participant through the perspective of a right-brain function (RBF). Certain products, such as premium automobiles (Rosengarten 2006), special jewelry, and elegant real estate, for example, are typically associated with a high-level of intangible service. As mentioned previously, the intangible value of a product may exceed its tangible value.

Primary and Secondary Service A primary service is the core service for which the provider and the client interact to produce demonstrable value. Simple examples are a dental appointment or a lawn care service. A secondary service is a service that does not exist separately as a primary service and plays a supportive role to a primary service. Common examples are the weigh in and blood pressure checks associated with a doctor's visit and the acceptance and delivery of garments at a dry cleaning establishment. Secondary service can also exist as a supplementary or referral service.

FACILITATING AND AuXiliary Service A facilitating service is disjoint from a primary or secondary service and enables a client to obtain utility from a tangible service. Usability service, commonly associated with automobiles and computers, is a common example of a facilitating service. Another common example of a facilitating service is the purchase of an event ticket. In this instance, the event - be it a visit to the theatre, sporting match, or an amusement park - is the tangible service and the ticket is the intangible service.

An auxiliary service is independent from a core service and may be experienced before or after the primary service. A blood test taken prior to a doctor's appointment and a medical referral are examples of auxiliary services.

SERVICE FUnCTIONS Many service functions relate to satisfaction models for consumer judgments regarding service interactions. One of two possible viewpoints is selected: expectation confirmation or rational utility assessment. With the expectation confirmation approach, the psychological distance between expectation and realization is measured. The tangible aspects of service are emphasized. With the rational utility approach, the tangible factors of service delivery, as well as the intangible factors, are taken into consideration. Tangible assessment is a means of referring to the demonstrable attributes of service delivery, such as product characteristics, skills of the service provider, and explicit service results as they pertain to people, possession, and information processing service. Tangible service results are utilitarian and measurable. Intangible assessment is a means of referring to the feeling that one experiences from a service interaction or the ownership of a product. Intangible service results are affective and hedonistic. The level of intangible service is normally a function of the feelings that one derives from ownership of a premium product or the participation in a service event with a particular service provider. The service functions are summarized in the DNA of a category of service, presented in the appendix and covered below.

\section{Service Process Lifecycle}

It is necessary to identify the key events in the operational service lifecycle and the major entities involved. The service lifecycle can be viewed as those activities that exist between service acquisition and service termination - from both structural and operational viewpoints. From the structural point-of-view, the set of layered activities 
incorporate the service commitment, service infrastructure, service availability, service delivery, and the eventual termination of a service, as delineated previously for the upper service ontology. From an operational point-ofview, the layered activities describe service events and incorporate those transactable actions that constitute the essence of service.

Based on the above definitions, the lifecycle of a service process consists of a loosely defined set of steps intended to co-create value for complementary service participants. It is useful to conceptualize a generic lifecycle for a domain ontology as consisting of the following steps:

- $\quad$ Service acquisition

- $\quad$ Service invocation

- $\quad$ Service execution

- $\quad$ Service termination

Service acquisition refers to the process of identifying a service provider with the requisite infrastructure, and its corollary, the process of attracting clients. Service invocation involves the scheduling and logistics part of the service process. Service execution entails the actual steps in the service process including supplementary services. Service termination incorporates referral, warranty, and archiving activities. The requisite infrastructure for sustaining the service process lifecycle is referred to as the service platform and is related to the activities of the producer in the upper ontology, covered previously. The service process lifecycle can be viewed as a set of layered events. We are going to supplement the service process lifecycle with service analytics that are descriptive of the end state of a service event.

\section{Service Acquisition}

The generic steps that comprise service acquisition represent the handshaking needed to establish a service relationship. From the client perspective, acquisition consists of an awareness that some form of service is needed, known as service awareness, followed by the discovery of a suitable delivery vehicle, called service discovery, perhaps using Web Services, and finally the development of a service level agreement, usually known as service negotiation. From the provider perspective, service acquisition is fueled by a service commitment, service availability, and a variety of service conditions incorporated in the DNA of that service category. Prototypical examples of service acquisition are finding a doctor in a new town or locating a shop for automobile repair.

In a discrete service, the service provider assumes the role of the "service producer" and the service client assumes the role of the "service requestor," in the sense that the client takes the initiative in the acquisition process. In professional and technical services, the service provider often assumes the role of the requestor by directly approaching from a business perspective or through direct advertising.

\section{Service Invocation}

An exogenous condition is needed to initiate a service process by the service provider on behalf of a service client. (Ferrario 2008) It is termed a triggering event that can take one of a variety of forms, such as:

- $\quad$ An independent event requiring attention, such as a medical situation or a fire

- A request by the client, or its representative, to have a service performed that the client doesn't want to do, can't do, or the provider can do more efficiently

- A required service, perhaps by law or convention, initiated by the client or a governing body

The triggering event is typically followed by a service scheduling process that establishes a spatiotemporal location for service delivery. Some service providers use appointments to manage demand as a means of achieving service efficiency. The steps that facilitate core or primary service invocation are customarily regarded as a secondary service. 
Service invocation involves back-office administrative record keeping and coordination, such that the provider and client can interact on a planned basis. The service delivery, availability, and demand dimensions of the service DNA sequence reflect the dynamics between provider and client in a service event. Appointments with professional service providers are formally scheduled, whereas arrangements with nonprofessionals are commonly scheduled on an informal basis.

\section{Service Execution}

Service execution is the phase of the service process lifecycle where the service provider engages the service client to achieve a goal state that reflects both provider and client perspectives. Alternately, the service object may be a service entity over which the client has legal or social responsibility. In general, the service object can be a person, a possession, information, or an abstract entity such as a financial investment. We are going to refer to the provider, the client, and the service object as service participants.

The primary objective of a service event is referred to as the core service that has tangible value to the service participants. The core service is conventionally comprised of primary, secondary, and auxiliary services, as described earlier under Basic Service Categories. We are going to establish five categories with which the execution of a service event, per se, can be determined:

\section{Category \\ Alternative}

\section{Modality \\ Diversity \\ Temporality \\ Complexity \\ Duration}

\author{
discrete, continuous \\ heterogeneous, homogeneous \\ active, passive \\ low complexity, high complexity \\ short, long
}

Modality denotes whether the texture of the service takes place as a single interaction (discrete), such as a doctor's visit that is over when it is over, or it takes place over an extended period of time (continuous), such as an insurance policy. Diversity refers to whether the service can be performed by a specific provider (heterogeneous), such as particular attorney or accountant, or any one of a group of providers (homogeneous), such as a bank teller. Temporality specifies whether the service is one in which the provider and client actively participate (active), such as a dentist's visit, or one in which the service participants are not actively engaged (passive) until a triggering event occurs, such as an insurance policy or a municipality's fire service. Complexity refers to whether the service is completed in a few similar steps (low complexity), or many different steps (high complexity). A hospital procedure or a home remodeling would reflect a high complexity; an appointment at the eye doctor's or a car detailing would exhibit low complexity. Duration, not to be confused with modality, refers to whether the service execution takes place in a few hours or less (short duration), or whether it takes place over a few days or longer (high duration). In medicine, a doctor's visit would have short duration, and a hospital stay would have long duration. In transportation, a ferry ride would have short duration, and a trans-Atlantic cruise would have long duration. Clearly, the collection of categories is generic and reflects the underlying difficulty in attempting to be specific with a ubiquitous social phenomena, such as service.

It is important to state the difference between DNA dimensions (see the Appendix) and categories of service execution. DNA dimensions are intended to describe and delineate the total service environment from the standpoint of upper and domain ontology. The categories of service execution are simply intended to provide specificity to the service process.

\section{Service Termination and Analytics}

Service termination and analytics encompasses follow-on activity, record keeping, archiving, and the financial aspects of service. Accordingly, this essential lifecycle element involves both front-office and back-office activities on the part of the provider and the client, leading to quality and value assessments. 
The service value analysis involves four components: provider's costs, provider's revenue, client's cost, client's revenue - recognizing that cost and revenue are not necessarily monetary. The fundamental theorem of service delivery applies to service analytics such that the cost of service by the provider must equal the value of commensurate service to the client, represented as:

$\mathrm{C}_{\mathrm{P}}=\mathrm{V}_{\mathrm{C}}$

where $\mathrm{C}_{\mathrm{P}}$ is the cost to the provider and $\mathrm{V}_{\mathrm{C}}$ is the value to the client. Accordingly,

$\mathrm{C}_{\mathrm{P}}=\mathrm{C}_{\mathrm{p}}+\mathrm{C}_{\mathrm{s}}+\mathrm{C}_{\mathrm{t}}$

where $\mathrm{C}_{\mathrm{p}}$ is the cost of primary core service, $\mathrm{C}_{\mathrm{s}}$ is the cost of secondary service, and $\mathrm{C}_{\mathrm{t}}$ are the transaction costs.

Similarly,

$\mathrm{V}_{\mathrm{C}}=\mathrm{V}_{\mathrm{t}}+\mathrm{V}_{\mathrm{i}}$

where $V_{t}$ is the value of tangible service and $V_{i}$ is the value of intangible service.

Analytics help the provider and the client answer fundamental questions, such as: Should we? (business value), Can we? (technology), May we? (governance), and Will we? (business priority).

\section{TAXONOMY OF SERVICE SYSTEMS}

This section delineates a taxonomy of service systems. A taxonomy essentially provides a prose glossary of a body of knowledge and a methodology for systems analysis and design. In this particular instance, the taxonomy of service systems supplies a lens into a collection of concepts, definitions, and relations that describe the complex subject of service science.

1. Service Identification

1.1 Service name

1.2 Sponsoring organization

1.3 Service initiation date

2. Service Participants

2.1 Service principal

2.2 Service producer

2.3 Service provider

2.4 Service client

2.5 Service object

3. Service System Lifecycle

3.1 Service commitment

3.2 Service production

3.3 Service availability

3.4 Service delivery

3.5 Service analysis

3.6 Service termination

4. Service Process

4.1 Service acquisition

4.1.1 Service awareness

4.1.2 Service discovery

4.1.3 Service negotiation

4.2 Service invocation

4.2.1 Triggering event

4.2.2 Service scheduling 
4.3 Service execution

4.3.1 Service participants

4.3.2 Service categories

4.3.2.1 Service modality

4.3.2.2 Service diversity

4.3.2.3 Service temporality

4.3.2.4 Service complexity

4.3.2.5 Service duration

4.3.2.6 Service DNA

4.4 Service termination

4.4.1 Provider costs

4.4.1.1 Core service

4.4.1.2 Secondary service

4.4.1.3 Auxiliary service

4.4.1.4 Transaction costs

4.4.2 Client value

4.4.2.1 Tangible value

4.4.2.2 Intangible value

In using the taxonomy of service systems, a service analyst would necessarily supply entries for each of the ontological elements, as required by a particular service system under investigation.

\section{SUMMARY}

An ontological introduction to the principles of service systems has been presented with an emphasis on concepts, classes, objects, relations, and terminology. The paper introduces social constructivism, as a basis of service science, and continues with service concepts, service systems, ontology, and then on to upper ontology for services, domain ontology for service, and finally a taxonomy of service systems, as well as a short treatise on a DNA of service.

\section{ACKNOWLEDGMENT}

Thanks to Margaret Katzan for reading the manuscript.

\section{REFERENCES}

1. Alter. S. 2008. Service system fundamentals: Work system, value chain, and life cycle. IBM System Journal, 47(1): 71-85.

2. Bergquist, W. 1993. Post Modern Thought in a Nutshell. [Published in Classics of Organization Theory (4 ${ }^{\text {th }}$ Edition - J. Shafritz and J. Ott, editors), New York: Harcourt Brace College Publishers, 1996. Adapted from Bergquist, W. 1993. The Postmodern Organization: Mastering the Art of Irreversible Change, JosseyBass Inc., Publishers, pp. 15-36.]

3. Boghossian, P. 2006. Fear of Knowledge: Against Relativism and Constructivism. Oxford: Oxford University Press.

4. Dedvedzic, V. 2002. Understanding Ontological Engineering. Communications of the ACM 45(4):136-144.

5. Ferrario, R. and N. Guardino. 2008. Towards an Ontological Foundation for Services Science. Proceedings of the Future Internet Symposium, Vienna Austria, 28-30 September 2008.

6. Fitzsimmons, J.A. and M.J. Fitzsimmons. 2006. Service Management: Operations, Strategy, Information Technology ( $5^{\text {th }}$ Edition), New York: McGraw-Hill Irwin.

7. Gruber, T. 2008. Ontology. Encyclopedia of Database Systems, Liu, L. and M. Ozsu (Eds.), SpringerVerlag,

8. Guarino, N. 1995. Formal Ontology, Conceptual Analysis and Knowledge Representation. International Journal of Human-Computer Studies, 43(5-6):907-928. 
9. IBM Almaden Services Research. 2006. "SSME: What are services?" Referenced from the following Web site: http://almaden.ibm.com/ssme.

10. Katzan, H. 2008a. Event Differentiation in Service Science. Journal of Business and Economics Research, 6(5): 141-152.

11. Katzan, H. 2008b. Service Science: Concepts, Technology, Management. New York: iUniverse, Inc.

12. Kuhn, T. 1996. The Structure of Scientific Revolution ( $3^{\text {rd }}$ edition), Chicago: University of Chicago Press. [Secondary reference]

13. Maglio, P. and J. Zysman. 2007. Toward a Science of Service Systems. Sofcon 2007. Carnegie Mellon University, April 30, 2007, pp. 5-6.

14. Newell, A., Perlis, A., and H.A. Simon. 1967. Computer Science. Science, 157: 1373-1374. [Secondary reference]

15. Sampson, S. and C. Froehle. 2006. Foundations and Implications of a Proposed Unified Services Theory. Productions and Operations Management, 15(2): 329-343.

16. Selznick, P. 1948. Foundations of the Theory of Organization. American Sociological Review 13: 25-35. [Published in Classics of Organization Theory ( $4^{\text {th }}$ Edition - J. Shafritz and J. Ott, editors), New York: Harcourt Brace College Publishers, 1996.]

17. Smith, A. 1776. The Wealth of Nations, published as "An Inquiry into the Nature and Causes of the Wealth of Nations" in London, England (1776).

18. Sowa, J. 2000. Knowledge Representation: Logical, Philosophical and Computational Foundations, Brooks Cole Publishing.

19. Spohrer, J., Anderson, L., Pass, N., Ager, T., and D. Gruhl. 2007a. Service Science. Journal of Grid Computing (Special Issue of Grid Economics and Business Models, August 2, 2007).

20. Spohrer. J., Vargo, S., Caswell, N., and P. Maglio. 2007b. The Service System is the Basic Abstraction of Service Science. IBM Almaden Research Center, http://www.almaden.ibm.com/asr.

21. Sutherland, J. 1975. Systems: Analysis, Administration, and Architecture. New York: Van Nostrand Reinhold Co.

22. Wikipedia. 2009. Ontology, www.wikipedia.org/ontology. 


\section{APPENDIX SERVICE CLASSIFICATION: A DNA of Service}

\section{Service Model}

In an ontological context, a service model distinguishes one form of service from another. To determine the inherent nature of a service, therefore, it is necessary to establish a conceptual framework in order to restrict our thinking to a particular area of awareness. The process is one of viewing the world through a special lens. Within this special world, we develop concepts that eventually lead to classes of service.

A concept is an abstract idea or mental representation that facilitates the recognition of and reference to objects in a specific area of interest. Concepts are important because they allow us to omit the differences between things by abstracting their common characteristics. Concepts lead to classes that lead to objects. A class is a material representation of a concept and an object is an instance of a class. Stated differently, objects with common characteristics are grouped into a class and are represented by a concept. We can work backwards from object to concept because we are dealing with socially constructed phenomena. Here is a hypothetical example from the personal service domain:

Service Universe: Service performed on a person

Service Concept: Medical provisioning

Service Class: Physician/patient

Service Event: Individual visit to the doctor

In this instance, the service model is "physician/patient" conceptualized as medical provisioning within the service universe "service performed on a person."

Because services are socially developed phenomena, differing levels of specificity are needed to satisfy the requirements of a given situation. Consider the concept of a teacher and two instances: kindergarten and college professor. The roles are so diverse that a service model would be expected for each. On the other hand, consider laundry service and dry cleaning. In this case, a single service model would be sufficient because both instances originate from a similar underlying conceptual structure.

\section{Service Classification}

IBM Almaden Service Research and Fitzsimmons and Fitzsimmons have identified five dimensions along which we can classify service: (IBM 2006 and Fitzsimmons 2006)

Service Process - using the degrees of Customer Interaction and Customization (by the provider) and Provider Judgment or Labor Intensity as metrics

Service Nature - using the Service Object and Service Result as metrics

Service Delivery - using Service Scheduling and Service Mode (continuous or discrete) as metrics

Service Availability - using Service Site and Service Execution (who travels - provider or client) as metrics

Service Demand - using Demand Fluctuation and Service Capacity as metrics

We can view the five dimensions as a service hyperspace that can be used as a service model generator. Table A.1 gives a summarization of the hyperspace using a quadrant-based scale.

\section{Service Dimensions}

Each dimension can be conceptualized as one view of a class of service, and collectively, the five dimensions define a service universe. The Service Process dimension is employed as an introductory example. Here is how it works. Each dimension can be viewed as a matrix, where the metrics and respective values are viewed using a Cartesian coordinate system. The Customer Interaction and Customization metric refers to the degree of specific attention given by the provider to the client during the entire service event. The Provider 
Judgment or Labor Intensity metric can refer to three possibilities: (1) The amount of time the client receives attention during the service process; and (2) The amount of time the provider is giving service when in the service process; and (3) The level of knowledge the provider brings to the service event. The service metrics are not precise in all cases; but it should be noted that our ultimate objective is to identify classes of service and not describe specific service events. This form of analysis will applies to other service dimensions.

We can apply the remaining service dimensions and the associated service metrics to a physician/patient example to achieve the following classification:

Service Process: $\quad$ Provider Judgment or Labor Intensity (high),

Service Nature: $\quad$ Service Result (tangible),

Service Result (tangible)
Service Object (people)

Service Delivery: $\quad$ Service Scheduling (formal),

Service Mode (discrete)

Service Availability: $\quad$ Service Site (single site),

Service Demand: $\quad$ Demand Fluctuation (narrow),

Service Capacity (not flexible)

The physician example is complete in the sense that we have created a conceptual view of a medical provisioning service along the five dimensions. It is important to recognize that a service model is not normative. A service model defines one point in a five dimensional Cartesian space representing a class of service.

\section{The DNA of Service}

The previous section introduced the notion of a five dimensional Cartesian space used to represent a service and establish a service model. (Katzan 2008a) In this section, we are going to introduce how the service hyperspace can be used to uniquely define classes of service. The DNA of service ${ }^{3}$ is used to delineate points in the service hyperspace. Each service model has a unique DNA sequence, based on the quadrant-based scale values for each of its dimensions. Moreover, the various dimensions have an order based on the dimension numbers given in Table A.1.

Recall the physician example presented earlier. From Table A.1, dimension \#1 (Service Process) has a DNA sequence value of $\mathbf{D}$, because its value for the metric Provider Judgment or Labor Intensity is High and the value for the metric Client Interaction and Customization is also High. Similarly, dimension \#2 (Service Nature) has a DNA sequence value of A, because its value for the metric Service Result is Tangible and the value for the metric Service Object is People. Using the same thinking, dimension \#3 (Service Delivery) has a DNA sequence value of $\mathbf{C}$; dimension \#4 (Service Availability) has a DNA sequence value of $\mathbf{A}$; and finally, dimension \#5 (Service Demand) has a DNA sequence value of $\mathbf{D}$. So the complete service DNA sequence for the physician model is DACAD. script:

As another example, the service customarily known as a "web search" is represented by the following

$\begin{array}{ll}\text { Service Process: } & \text { Provider Judgment or Labor Intensity (high), } \\ & \text { Client Interaction and Customization (low) } \\ \text { Service Nature: } & \text { Service Result (tangible), } \\ & \text { Service Object (information) } \\ \text { Service Delivery: } & \text { Service Scheduling (informal), } \\ & \text { Service Mode (discrete) }\end{array}$

${ }^{3}$ In this instance, DNA is an acronym recursively defined as "DNA is Never Ambiguous." 
Service Availability: $\quad$ Service Site (single site),

Service Demand:

Service Execution (no travel)

Demand Fluctuation (wide),

Service Capacity (flexible)

Table A.1 Quadrant-Based Scale for the Five Dimensions in Service Hyperspace

Dimension \#1: Service Process

Provider Judgment/Labor Intensity $\underline{\text { Customer Interaction/Customization } \quad \text { Quadrant-Based Scale }}$

$\begin{array}{lll}\text { Low } & \text { Low } & \text { A } \\ \text { Low } & \text { High } & \text { B } \\ \text { High } & \text { Low } & \text { C } \\ \text { High } & \text { High } & \text { D }\end{array}$

Dimension \#2: Service Nature

$\underline{\text { Service Result }}$

$\underline{\text { Service Object }}$

Quadrant-Based Scale

Tangible

Tangible

People

Possessions

Intangible

Intangible

Tangible

People

Possessions

Information

A

Intangible

Information

A
B
C
D
E
F

Dimension \#3: Service Delivery

$\underline{\text { Service Mode }}$

$\underline{\text { Service Scheduling }}$

Quadrant-Based Scale

Continuous

Continuous

Discrete

Formal

Informal

Formal

Informal

A

B

Discrete

$\underline{\text { Service Site }}$

Single Site

Multiple Sites

Single Site

Multiple Sites

Single Site

Multiple Sites

Dimension \#5: Service Demand

Service Capacity

Flexible

Flexible

Not Flexible

Not Flexible
Demand Fluctuation

Wide

Narrow

Wide

Narrow

\section{Quadrant-Based Scale}

A
B
C
D
E
F

Quadrant-Based Scale

A

B

C

D 
The key attributes of this kind of service are that neither the client nor the provider travels, and the labor intensity is high, because sophisticated software is required, but the service is normally not customized for each client. The activity is not scheduled and takes a finite time. The demand varies widely and the provider usually has unlimited capacity to perform the service. The service DNA sequence for this service model is CEDEA.

\section{Models, Classes, and Objects}

Each service model can be uniquely identified by a service DNA sequence. If two service models have the same service DNA sequence, then they are in the same class, as defined previously. We can also construct a service DNA sequence representing a service class with no instances (i.e., objects). Because service systems are socially constructed forms of knowledge, we are not constrained by nature to describe only what exists. We can be innovative and design service systems to satisfy a variety of needs.

\section{Brief Summary}

Service concepts lead to classes that lead to objects. A class is a material representation of a concept and an object is an instance of a class. Objects are usually distinguished by their attributes, and classified by the same or different attributes. Using service attributes, five service dimensions have been identified: Service Process, Service Nature, Service Delivery, Service Availability, and Service Demand. The five dimensions are used as service model generators. A quadrant scale is developed so that a DNA of Service, based on the dimensions and the scale, is feasible. In the physician/patient model, for example, the service DNA sequence would be DACAD. The service DNA sequence gives some options for service innovation. 